\title{
Natural history and prognostic factors in 305 Swedish patients with primary sclerosing cholangitis
}

U Broomé, R Olsson, L Lööf, G Bodemar, R Hultcrantz, Å Danielsson, H Prytz, $\mathrm{H}$ Sandberg-Gertzén, $S$ Wallerstedt, G Lindberg

\begin{abstract}
Background/Aims-The course of primary sclerosing cholangitis (PSC) is highly variable and unpredictable. This study describes the natural history and outcome of PSC. These data were used to construct a prognostic model for patients with PSC.

Methods-A total of 305 Swedish patients with PSC were studied. The median follow up time was 63 (1-194) months and all patients could be traced for follow up. Some 79 patients died or had a liver transplant. The prognostic significance of clinical, biochemical, and histological findings at the time of diagnosis were evaluated using multivariate analysis.

Results-The estimated median survival from time of diagnosis to death or liver transplantation was 12 years. Cholangiocarcinoma was found in $24(8 \%)$ of the patients and $134(44 \%)$ of the patients were asymptomatic at the time of diagnosis. The estimated survival rate was significantly higher in the asymptomatic group $(p<0.001)$. However, $29(22 \%)$ of the asymptomatic patients became symptomatic during the study period. It was found that age, serum bilirubin concentration, and histological stage at the time of diagnosis were independent predictors of a bad prognosis. These variables were used to construct a prognostic model. Conclusions-This prognostic model developed from a large homogeneous population of PSC patients should be of value for the timing of transplantation and patient counselling in PSC.

(Gut 1996; 38: 610-615)
\end{abstract}

Keywords: ulcerative colitis, prognostic models, liver transplantation, cholangiocarcinoma.

Primary sclerosing cholangitis (PSC) is a chronic biliary destructive disease of unknown aetiology. The natural history is highly variable, some patients being asymptomatic for years, others rapidly progressing to premature death resulting from liver failure or cholangiocarcinoma. ${ }^{2}$ There is no effective treatment. With optimal timing for liver transplantation, however, excellent results have been achieved. ${ }^{3-6}$ It is therefore of importance to develop prognostic models that can be used to classify patients for therapeutic trials, for timing of liver transplantation, as well as in the counselling of patients. The results of studies from large referral centres are conflicting because of differences in sample size, referral patterns, definition of start and end point of the disease but may also be because of ethnic differences. ${ }^{7-10}$

PSC is a heterogeneous disease and therefore it is important to describe the natural history and factors of prognostic importance in a homogeneous population.

The aim of this retrospective study was threefold: (a) to describe the natural history and outcome for 305 PSC patients of Swedish descent; (b) to evaluate the prognostic significance of clinical, biochemical, and histological findings at the time of diagnosis using multivariate analysis; and (c) to construct a prognostic model.

\section{Methods}

\section{Patients}

Three hundred and five patients of Swedish descent with PSC were included in the study. The patients were treated by doctors who are members of the Swedish Internal Medicine Liver Club (SILK) at nine hospitals throughout Sweden. The hospitals all serve both as primary and referral hospitals. Liver transplantation in Sweden is only performed at Huddinge and Sahlgrenska hospitals, both centres participating in the study. All patients that have been personally treated by the respective investigators were included in the study. The data were collected and verified using a questionnaire agreed upon in all centres by the investigators.

\section{Diagnosis}

The diagnosis of PSC was based on typical cholangiographic findings in all patients in combination with clinical, histological, and laboratory data. ${ }^{11} 12$ The cholangiographic techniques used were either endoscopic retrograde $(n=266)$, percutaneous transhepatic $(n=9)$ or operative $(n=30)$. The confluence of the bile ducts at the hilum was used to distinguish between the extra and intrahepatic biliary system.

Clinical, histological, and biochemical variables Symptoms and signs including jaundice, right upper quadrant pain, pruritus, fever, ascites, and variceal haemorrhage were recorded at the

Correspondence to: Dr U Broomé, Departmen of Gastroenterology and Hepatology, K63, Hudding Huddinge, Sweden. 
time of diagnosis and at follow up. Patients were classified according to the presence of symptoms at diagnosis as asymptomatic or symptomatic. Histological staging was based on previously established criteria. ${ }^{13}$ For the regression analysis, all biopsy specimens were restaged according to the Mayo Clinic model using value 1 for stage I and II, 2 for stage III, and 4 for stage IV. ${ }^{8}$ The diagnosis of cholangiocarcinoma was based on histological examination.

Biochemical analyses including total bilirubin, albumin, alkaline phosphatase, aspartate and alanine aminotransferases were performed using standardised techniques at the local hospital. Evidence for inflammatory bowel disease (IBD) was investigated by sigmoidoscopy, colonoscopy or barium enema in all patients. A diagnosis of ulcerative colitis (UC) and Crohn's disease (CD) was based on accepted criteria. ${ }^{1415}$

\section{Statistical methods}

The starting point of the disease was defined as the time of typical findings at cholangiography. The time of onset of persistently abnormal liver function tests was also recorded. End point was either death from liver disease or liver transplantation. The patients were studied until the end of 1992 . The $\chi^{2}$ test or Student's $t$ test for continuous variables were used to compare differences between symptomatic and asymptomatic patients, referred and non-referred patients, and patients with and without cholangiocarcinoma. Kaplan-Meier analysis was used to calculate actuarial survival. The prognostic significance of different variables present at the time of diagnosis was analysed using the Cox proportional hazard model. A prognostic model was constructed with factors found to be of independent prognostic value.

\section{Results}

\section{General characteristics}

Among the 305 patients, 195 were males (64\%) and 110 females; 146 (48\%) patients came from the primary catchment area of each hospital, whereas 159 patients had been referred from hospitals in other areas of the country. The median age at the time of diagnosis was 39 (range 5-80) years. The median delay from the first presentation of biochemical signs or symptoms compatible with PSC until the time of diagnosis was 52 (range 0-451) months. Most, 203 (67\%), of the patients had both intra and extrahepatic PSC, whereas 83

TABLE I Symptoms presented at time of PSC diagnosis

\begin{tabular}{lc}
\hline & Number (\%) \\
\hline Symptomatic patients & $171(56)$ \\
Abdominal pain & $112(37)$ \\
Jaundice & $91(30)$ \\
Pruritus & $90(30)$ \\
Fever & $52(17)$ \\
Ascites & $10(4)$ \\
Variceal haemorrhage & $10(4)$ \\
\hline
\end{tabular}

(27\%) had intrahepatic involvement only, and $19(6 \%)$ had only extrahepatic PSC. In 249 $(81 \%)$ patients, PSC was associated with IBD: $220(72 \%)$ had UC, $20(7 \%)$ had CD, and nine $(2 \%)$ had unspecific colitis. Among the patients with $C D, 12$ had involvement of the colon only and in eight patients the disease was found in both the small bowel and the colon. Seventy four patients (30\%) with IBD had previously undergone proctocolectomy. Patients without IBD were significantly older at the time of PSC diagnosis than the patients with IBD $(44.8 v 38.5$ years, $\mathrm{p}<0.002)$. Sex, number of patients with intra/extrahepatic distribution of disease, observation time, time to diagnosis, and development of cholangiocarcinoma did not differ between patients with and without an associated IBD.

\section{Symptoms}

At the time of diagnosis, 171 (56\%) patients had one or more of the symptoms listed in Table 1. The most common symptom was pain localised to the right upper quadrant, described by $112(37 \%)$ patients. During a median observation period of 69 months, 29 $(22 \%)$ of the asymptomatic became symptomatic.

\section{Laboratory and histological findings at time of diagnosis}

The bilirubin concentration was normal in 179 $(59 \%)$ patients at the time of diagnosis and the mean figure for the whole group was 39 $\mu \mathrm{mol} / \mathrm{l}$. Alkaline phosphatase activity was normal in $26(8.5 \%)$ patients and the average for the group was $18 \mu \mathrm{kat} / \mathrm{l}$ (Table II). Liver biopsy was carried out in 254 patients at the time of diagnosis and stage I or II was present in $118(46 \%)$, stage III in $73(28 \%)$, and liver cirrhosis (stage IV) in $67(26 \%)$.

\section{Asymptomatic and symptomatic patients}

Table II shows data from patients with and without symptoms at the time of diagnosis. Significantly more women than men were found in the symptomatic group and patients with symptoms were older than asymptomatic ones at the time of diagnosis. The prevalence of an associated IBD differed significantly between the two groups and almost all asymptomatic patients had an IBD, probably reflecting the fact that most IBD patients in Sweden are regularly screened with liver function tests. Furthermore, PSC has actively been looked for in UC. ${ }^{16}$ There was no difference between the groups in time from first presentation of abnormal liver function tests until the diagnosis of PSC was established with a cholangiogram. The observation time for the asymptomatic group was slightly longer than for the symptomatic group. Symptomatic patients had significantly higher serum values of bilirubin, aspartate aminotransferase and alkaline phosphatase, and lower values of albumin than those without symptoms. 
TABLE II Clinical and biochemical features in 305 PSC patients who were asymptomatic and symptomatic respectively at the time of diagnosis

\begin{tabular}{|c|c|c|c|c|}
\hline & $\begin{array}{l}\text { All patients } \\
(n=305)\end{array}$ & $\begin{array}{l}\text { Patients } \\
\text { symptomatic } \\
\text { at time of } \\
\text { diagnosis } \\
(n=171)\end{array}$ & $\begin{array}{l}\text { Patients } \\
\text { asymptomatic } \\
\text { at time of } \\
\text { diagnosis } \\
(n=134)\end{array}$ & $\begin{array}{l}\text { p Value } \\
\text { (comparison } \\
\text { symptomatic and } \\
\text { asymptomatic } \\
\text { patients) }\end{array}$ \\
\hline $\begin{array}{l}\text { Age at diagnosis }(\mathrm{y}) \text { (mean }(\mathrm{SD})) \\
\text { Male }(\%) \\
\text { IBD }(\%) \\
\text { Extra hepatic involvement of the biliary tree }(\%) \\
\text { Follow up (months) (SD) } \\
\text { Death or transplantation }(\%) \\
\text { Cirrhosis }(\%) \\
\text { Bilirubin }(<21 \mu \mathrm{mol} / \mathrm{l})(\text { mean }(\mathrm{SEM})) \\
\text { Alkaline phosphatase }(<4 \cdot 2 \mu \mathrm{kat} / \mathrm{l})(\text { mean }(\mathrm{SEM})) \\
\text { Aspartate aminotransferase }(<0 \cdot 80 \mu \mathrm{kat} / \mathrm{l})(\text { mean }(\mathrm{SEM})) \\
\text { Albumin }(35-46 \mathrm{~g} / \mathrm{l})(\text { mean }(\mathrm{SEM}))\end{array}$ & $\begin{array}{l}39(14) \\
195(64) \\
249(81) \\
222(72) \\
63(47) \\
79(26) \\
67(22) \\
39(3 \cdot 55) \\
13(0 \cdot 78) \\
2 \cdot 1(0 \cdot 15) \\
38(0 \cdot 47)\end{array}$ & $\begin{array}{l}41(13 \cdot 3) \\
98(57) \\
126(74) \\
138(80) \\
59(48) \\
62(36) \\
50(29) \\
57(5 \cdot 86) \\
20 \cdot 7(1 \cdot 19) \\
2 \cdot 5(0 \cdot 24) \\
37(0 \cdot 60)\end{array}$ & $\begin{array}{l}37(14 \cdot 6) \\
97(72) \\
123(92) \\
84(63) \\
69(46) \\
17(13) \\
17(13) \\
16(1 \cdot 12) \\
14(0 \cdot 8) \\
1 \cdot 7(0 \cdot 15) \\
40(0 \cdot 72)\end{array}$ & $\begin{array}{l}p<0.05 \\
p<0.001 \\
p<0.001 \\
p<0.001 \\
p<0.05 \\
p<0.001 \\
p<0.01 \\
p<0.001 \\
p<0.001 \\
p<0.01 \\
p<0.01\end{array}$ \\
\hline
\end{tabular}

Referred and non-referred patients at the time of PSC diagnosis

Clinical and epidemiological data concerning age, sex, follow up time, presence of IBD, and symptoms did not differ between referred and non-referred patients.

\section{PSC and cholangiocarcinoma}

There was no significant difference between the patients who developed cholangiocarcinoma and those who did not with respect to sex, age at presentation, extra or intrahepatic involvement of the biliary disease, or associated IBD. Nine of 24 patients who developed cholangiocarcinoma did so within one year after the PSC diagnosis. As the presenting features of these nine patients could have been caused by the cholangiocarcinoma, these patients were excluded from the comparisons regarding symptoms and biochemical tests. The only symptom that occurred significantly more often at time of diagnosis in the cholangiocarcinoma group than in the tumour free group was abdominal pain $(59 \% v$ $35 \%)(p<0.01)$. Serum bilirubin at diagnosis was higher in the patients who later developed cholangiocarcinoma $(82.9 \quad v \quad 35.1 \mu \mathrm{mol} / \mathrm{l})$ $(\mathrm{p}<0.005)$.

\section{Follow up}

At follow up in 1992, information was available for all 305 patients. The median follow up

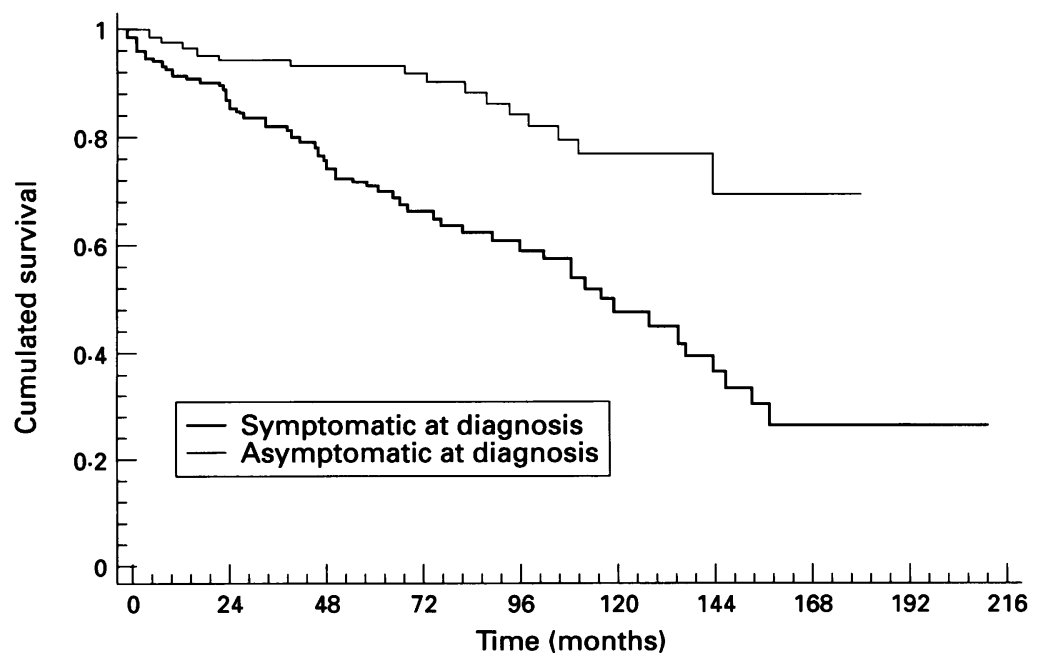

Figure 1: Kaplan-Meier estimated survival curves of symptomatic and asymptomatic PSC patients $(p<0.001)$. time to death, transplantation, or closing of the study was 63 (1-211) months. At follow up, $226(74 \%)$ patients were alive and had not had a transplant 66 (range 1-211) months after diagnosis, 45 (14\%) had died after 51 (range $1-154)$ months, and 34 (11\%) had had liver transplantation 62 (range 1-137) months after diagnosis. Twenty nine $(64 \%)$ of all deaths were caused by liver failure. Furthermore, four patients died in massive variceal haemorrhage. Cholangiocarcinoma was the main cause of death in 12 patients; when the patients who had had a transplant were included cholangiocarcinoma was diagnosed in $24(8 \%)$ patients, 32.5 (1-154) months after the diagnosis of PSC. There were no differences in time from the first findings consistent with PSC until the diagnosis was confirmed with a cholangiogram between patients developing and not developing cholangiocarcinoma. Thus, among the 79 patients who died or underwent liver transplantation, cholangiocarcinoma was diagnosed in $24(30 \%)$. In the whole group of patients with a follow up $>$ five years $16 \%$ developed cholangiocarcinoma. Only $69 \%$ of all patients who died had a necropsy, but all livers removed at liver transplantation were, however, carefully examined for cholangiocarcinoma. Among the 65 patients who died and had a necropsy or had a liver transplant 19 $(29 \%)$ had cholangiocarcinoma.

\section{Survival analysis}

The estimated median survival time for the whole PSC group was 144 months. KaplanMeier survival curves showed a significantly better median survival for the asymptomatic patients than for those who were symptomatic at the time of diagnosis (112 months) $(p<0.001)$ (Fig 1).

\section{Univariate and multivariate analysis}

The prognostic value of 19 variables present at the time of diagnosis were studied using univariate analysis (Table III). Variables found to be of prognostic significance by univariate analysis were entered into a multivariate analysis. Symptoms were also tested in combination with each other. Using backward elimination as well as forward selection, four variables available at diagnosis of PSC were found to be of independent prognostic value: 
TABLE III Prognostic significance of variables at time of PSC diagnosis entered into univariate Cox regression procedure

\begin{tabular}{|c|c|c|c|c|}
\hline Variable & $\begin{array}{l}\text { Patients } \\
\text { (n) }\end{array}$ & $\begin{array}{l}\text { Relative } \\
\text { risk }\left(e^{\beta}\right)\end{array}$ & $\begin{array}{l}\text { Confidence } \\
\text { intervals }\end{array}$ & $\stackrel{p}{\text { Value }}$ \\
\hline \multicolumn{5}{|l|}{ Demographic } \\
\hline Age & 305 & 1.03 & 1.01 to 1.04 & $<0.001$ \\
\hline Sex & 305 & $1 \cdot 19$ & 0.75 to 1.80 & NS \\
\hline \multicolumn{5}{|l|}{ Clinical } \\
\hline Associated IBD & 305 & 0.98 & 0.54 to 1.66 & NS \\
\hline Extrahepatic PSC & 304 & $3 \cdot 38$ & 1.62 to 7.03 & $<0.001$ \\
\hline Abdominal pain & 303 & 1.65 & 1.06 to 2.58 & $<0.05$ \\
\hline Fever & 302 & 1.51 & 0.88 to 2.57 & $<0.05$ \\
\hline Jaundice & 304 & 4.09 & 2.55 to 6.54 & $<0.001$ \\
\hline Pruritus & 301 & $2 \cdot 26$ & 1.42 to 3.60 & $<0.001$ \\
\hline Ascites & 302 & $6 \cdot 38$ & $2 \cdot 88$ to $14 \cdot 3$ & $<0.001$ \\
\hline Variceal bleeding & 303 & $6 \cdot 23$ & 2.96 to 13.10 & $<0.001$ \\
\hline \multicolumn{5}{|l|}{ Biochemical } \\
\hline Bilirubin ( $\log _{2}$ value) & 297 & 1.64 & 1.42 to 1.89 & $<0.001$ \\
\hline Aspartate aminotransferase & 292 & 1.09 & 1.03 to 1.15 & $<0.01$ \\
\hline AST ( $\log _{2}$ value) & 292 & 1.43 & 1.20 to 1.69 & $<0.001$ \\
\hline Alanine aminotransferase & 291 & 1.03 & 1.00 to 1.03 & $<0.05$ \\
\hline ALT ( $\log _{2}$ value) & 291 & $1 \cdot 11$ & 0.93 to 1.31 & NS \\
\hline Alkaline phosphatase & 299 & 1.02 & 1.01 to 1.03 & $<0.01$ \\
\hline ALP (log, value) & 299 & 1.43 & 1.17 to 1.76 & $<0.001$ \\
\hline Albumin & 217 & 0.94 & 0.96 to 1.04 & $<0.001$ \\
\hline Histological stage ${ }^{\star}$ & 257 & $1 \cdot 44$ & 1.05 to 1.54 & $<0.001$ \\
\hline
\end{tabular}

^For stages 1 and 2 , use 1 ; for stage 3 , use 2 ; for stage 4 , use 4 .

TABLE IV Prognostic model for Swedish patients with PSC without a history or variceal haemorrhage

\begin{tabular}{lllll}
\hline Variable & $\begin{array}{l}\text { Regression } \\
\text { coefficient }\end{array}$ & $\begin{array}{l}\text { Standard } \\
\text { error }\end{array}$ & $\begin{array}{l}\text { Confidence } \\
\text { intervals }\end{array}$ & $\begin{array}{l}p \\
\text { Value }\end{array}$ \\
\hline Histology & 0.24 & 0.096 & 1.05 to 1.54 & $<0.01$ \\
Age & 0.03 & 0.010 & 1.01 to 1.04 & $<0.05$ \\
Log $_{2}$ bilirubin & 0.49 & 0.080 & 1.42 to 1.89 & $<0.001$ \\
\hline
\end{tabular}

${ }^{\star}$ For stages 1 and 2 use 1 ; for stage 3 use 2; for stage 4 use 4 .

age, histological stage, serum bilirubin concentration, and a history of variceal haemorrhage. As a history of variceal haemorrhage (occurring in only $4 \%$ of all patients) in itself strongly indicated poor survival (median 28 months), patients who had bled were excluded from the construction sample for the prognostic index (Table IV).

\section{Prognostic index}

A prognostic index (PI) was constructed from the three variables identified with multivariate analysis using the regression coefficients presented in Table IV, resulting in the equation: $\mathrm{PI}=0.24 \times$ histology stage $+0.03 \times$ age $+0.49 \times$ $\log _{2}$ bilirubin. Histology stage $\mathrm{I}+\mathrm{II}=1$, stage $\mathrm{III}=2$, and $\mathrm{IV}=4$. Age is age in years and $\log _{2}$ bilirubin is logarithm ${ }_{2}$ of serum bilirubin concentration $(\mu \mathrm{mol} / \mathrm{l})$.

The PI for a hypothetical example of a 30

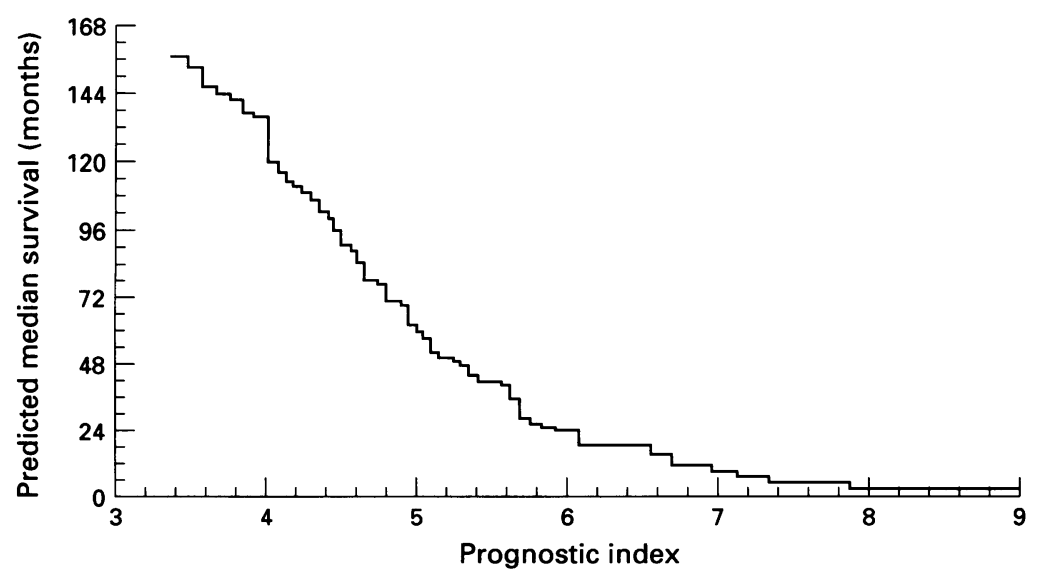

Figure 2: A graph of estimated median survival plotted against prognostic index. year old man with stage 1 on liver biopsy and serum bilirubin concentration of $22 \mu \mathrm{mol} / 1$ is calculated:

$P I=0.24 \times 1+0.03 \times 30+0.49 \times \log _{2}=3.33$.

In Fig 2, a graph of estimated median survival is plotted against the prognostic index.

\section{Discussion}

This study describes the natural history of 305 PSC patients from Sweden, a country with approximately eight million inhabitants. In comparison 174 PSC patients from the United States and 126 from England, countries with considerably greater numbers of people have been presented. ${ }^{89}$ The prevalence of PSC in Swedish patients with UC has previously been described. ${ }^{16}$ If the prevalence of UC is around $150 / 100000$ inhabitants and approximately $5 \%$ of all UC patients have PSC, this study comprising 305 PSC patients represents approximately $40-50 \%$ of all PSC patients in Sweden.

Our material differs from that of the American and English studies in its high percentage of patients from the primary catchment area, probably giving a more representative reflection of the natural history of PSC.

The general characteristics of the patients in this study resemble those found in Norway, England, and the United States with a male predominance, a mean onset of disease around 40 years of age with a very large span $(5-80$ years) with respect to the age at diagnosis, and a close association with IBD. ${ }^{8917}$ It can be argued that the inclusion of unspecified colitis (nine patients, 2\%) into the IBD group is unjustified, but during the observation time some of the patients with unspecified colitis were reclassified as suffering from UC or CD. Thus, the prevalence of IBD is $81 \%$ in this study whereas results of studies from the United States show (71\%), ${ }^{8}$ England $(71 \%),{ }^{9}$ and Norway $(100 \%) .{ }^{17}$ The Norwegian study is the only one in which all patients underwent colonoscopy and patients with unspecified colitis were included.

Twenty seven per cent of the patients in this study had intrahepatic PSC only. This is in agreement with a study from Yale, ${ }^{7}$ but in contrast with studies from both the Mayo $\mathrm{Clinic}^{8}$ and King's College Hospital ${ }^{9}$ showing a considerably lower percentage of patients with intrahepatic PSC only. Although real differences may exist between the various PSC populations, there may also be differences in anatomical definition of the extra and intrahepatic ductal system.

The important differences between the PSC populations in the various studies seem, however, not to be found in the general characteristics of the patients but rather in the severity of the disease. In four studies describing the natural history of PSC the number of asymptomatic patients ranged from $15-25 \%,{ }^{7-10}$ whereas a figure of $44 \%$ was noted in our study. Differences concerning definition of symptoms do exist between the previous studies. Fatigue was defined as a symptom in 
some studies ${ }^{79}$ but not in this one because of problems in defining this subjective symptom retrospectively. In the study by Farrant et al, ${ }^{9}$ fatigue was the most common symptom, reported by $65 \%$ of the patients.

This study comprises the largest number of asymptomatic PSC patients described; this may in part be explained by the high rate of patients with PSC restricted to the intrahepatic biliary tree, as $60 \%$ of these patients were asymptomatic. Significant differences between asymptomatic and symptomatic patients were found in survival, biochemical, and histological parameters, but also with respect to age at presentation and sex. Survival rate for the asymptomatic groups was $70 \%$ at 16 years after diagnosis (Fig 1). This benign course for the asymptomatic group is in agreement with the study by Heltzberg. ${ }^{7}$ However, $22 \%$ of all asymptomatic patients developed symptoms during a median observation time of 69 months, and approximately $13 \%$ of the asymptomatic patients died or had liver transplants. This emphasises the progressive nature of PSC even in the asymptomatic group.

Despite the pronounced differences in survival between symptomatic and asymptomatic patients, the only symptom that was found to be of independent prognostic significance using multivariate analysis was variceal haemorrhage, which occurred in only $4 \%$ of all patients.

Differences in both definition of start and end point of the disease may influence actuarial survival time in different studies. In the study from King's College Hospital, reporting an estimated median survival time of 12 years, the start point of disease was defined as the onset of abnormal liver function test or signs compatible with PSC. ${ }^{9}$ In our study an average of 52.5 months elapsed from onset of abnormal liver biochemistry until the diagnosis was confirmed with a cholangiogram. The median survival time would probably therefore be longer if we had used King's definition of start point. As $81 \%$ of our patients had an associated IBD and activity of the colitis, and as treatment with drugs for the bowel disease and parenteral nutrition can cause abnormal liver function tests, we defined the start point of disease as the time of cholangiographic diagnosis. ${ }^{18}$ The Mayo Clinic study reporting an estimated median survival time of 11.9 years, defined start point as date of referral to the Clinic. ${ }^{810}$ As $59 \%$ of all patients were jaundiced at time of referral to the Mayo Clinic compared with $30 \%$ in this study, the disease process was probably more advanced at inclusion in the Mayo study.

End points in the various prognostic studies comprise both date for liver related deaths and liver transplantation or include only liver related deaths. The addition of liver transplantation as an end point in this study was chosen because over $30 \%$ of Swedish PSC patients submitted for liver transplantation died while waiting for a liver transplant. ${ }^{19}$

The reliability of a description of the natural history of a disease depends upon the size of a patient cohort in relation to the size of the background population. The importance of sample size may well be illustrated in the multicentre study presented by Dickson et al. ${ }^{10}$ The prognostic significance of different variables was calculated for 426 PSC patients. For most of these patients, prognostic factors had been calculated in smaller separate studies. The factors found to be of prognostic importance in the large multicentre study differed from those identified in the smaller studies. The multicentre study showed that serum bilirubin concentration, histological stage at liver biopsy, age and, the presence of splenomegaly were independent predictors of high risk of dying. In our study with a large number of patients, bilirubin concentration, histological stage, and age were all factors found to be of prognostic significance.

The presence of splenomegaly was not evaluated in this study. The most accurate way to determine enlargement of the spleen is with isotopic scan, computed tomography or ultrasound. Although, one of these investigations had usually been done in our patients, the investigation had usually not been done at the same time as the time of diagnosis or the size of the spleen had not been described.

No investigated factors in this study could identify those PSC patients who would later develop cholangiocarcinoma. The detection rate of cholangiocarcinoma in $8 \%$ of the patients is comparable with that of other studies. It is probably an underestimation, however, as $31 \%$ of all patients who died did not have a necropsy. Furthermore, cholangiocarcinoma is often difficult to diagnose in living patients with PSC. 891820 Perhaps the introduction of time dependent variables into a dynamic prognostic model could be of value in the identification of PSC patients at risk for malignant transformation of the bile ducts. ${ }^{21}$

We conclude that although genetic differences exist concerning HLA class II antigen association between Swedish, American, and English patients, ${ }^{22-26}$ the natural history and factors of prognostic importance seem more to be related to selection bias and sample size than to real differences between PSC patients from different countries.

The authors acknowledge the financial support by G D Searle The
Ltd.

1 Chapman RW, Burroughs AK, Bass NM, Sherlock S. Long-standing asymptomatic primary sclerosing cholangitis: report of three cases. Dig Dis Sci 1981; 26: 778-82.

2 Rosen CB, Nagorney DM, Wiesner RH, Coffey R Jr, La Russo NF. Cholangiocarcinoma complicating primary sclerosing cholangitis. Ann Surg 1991; 213: 21-5.

3 Marsh J Jr, Iwatsuki S, Makowka L, Esquivel CO, Gordon $\mathrm{RD}$, Todo $\mathrm{S}$, et al. Orthotopic liver transplantation for primary sclerosing cholangitis. Ann Surg 1988; 207: 212-5.

4 Krom RAF, Wiesner RH, Rettke SR, Ludwig J, Southorn PA, Hermans PE, et al. The first 100 liver transplantations at the Mayo Clinic. Proc Mayo Clin 1989; 64: 89-94.

5 Langnas AN, Grazi GL, Stratta RJ, Wood RP, Marujo W, Markin RS, et al. Primary sclerosing cholangitis: the emerging role for liver transplantation. Am $\mathcal{f}$ Gastroenterol 1990; 85: 1136-41.

6 Wiesner RH, Porayko MK, Dickson ER, Gores GJ, La Russo NF, Hay JE, et al. Selection and timing of liver transplantation in primary biliary cirrhosis and primary sclerosing cholangitis. Hepatology 1992; 16: 1290-9.

7 Heltzberg JH, Petersen JM, Boyer JL. Improved survival with primary sclerosing cholangitis. A review of clinicopathologic features and comparison of symptomatic and asymptomatic patients. Gastroenterology 1987; 92:
1869-75. 
8 Wiesner RH, Grambsch PM, Dickson R, Ludwig J, MacCarty RL, Hunter EB, et al. Primary sclerosing cholangitis: natural history, prognostic factors and survival analysis. Hepatology 1989; 10: 430-6.

9 Farrant JM, Hayllar KM, Wilkinson ML, Karani J, Portmann BC, Westaby D, et al. Natural history and prognostic variables in primary sclerosing cholangitis. Gastroenterology 1991; 100: 1710-7.

10 Dickson ER, Murtaugh PA, Wiesner RH, Grambsch PM, Fleming TR, Ludwig J, et al. Primary sclerosing cholangitis: refinement and validation of survival models. gitis: refinement and validation of

11 Chapman RWG, Arborgh BAM, Rhodes JM, Summerfield JA, Dick R, Scheuer PJ, et al. Primary sclerosing cholangiJA, Dick R, Scheuer PJ, et al. Primary sclerosing cholangi-
tis; a review of its clinical features, cholangiography and tis; a review of its clinical features, cho
hepatic histology. Gut 1980; 21: 870-7.

12 Wiesner RH, LaRusso NF. Clinicopathologic features of the syndrome of primary sclerosing cholangitis. Gastroenterology 1980; 79: 200-6.

13 Ludwig J, Barham SS, La Russo NF, Elveback LR, Wiesner RH, McCall JT. Morphologic features of chronic hepatitis associated with primary sclerosing cholangitis and chronic ulcerative colitis. Hepatology 1981; 1: 632-40.

14 Evans JG, Acheson ED. An epidemiological study of ulcerative colitis and regional enteritis in the Oxford area. Gut 1965; 6: 311-24.

15 Farmer RG, Mawic WA, Turnbull RR. Clinical patterns in Crohn's disease: a statistical study of 6155 cases. Gastroenterology 1975; 68: 627-35.

16 Olsson R, Danielsson A, Järnerot $G$, Lindström E, Lööf L, Rolny $\mathrm{P}$, et al. Prevalence of primary sclerosing cholangitis in patients with ulcerative colitis. Gastroenterology 1991; 100: 1319-23

17 Aadland E, Schrumpf E, Fausa O, Elgjo K, Heilo A, Aakhus $\mathrm{T}$, et al. Primary sclerosing cholangitis: a long-term follow-up study. Scand f Gastroenterol 1987; 22: 655-64.
18 Broomé U, Glaumann H, Hellers G, Sörstad J, Nilsson B, Hultcrantz R. Liver disease in ulcerative colitis. An epidemiological and follow-up study in the county of Stockholm. Gut 1994; 35: 84-9.

19 Bromé U, Ljusk Eriksson S. Assessment for liver transplantation in patients with primary sclerosing cholangitis. f Hepatol 1994; 20: 654-9.

20 Miros M, Kerlin P, Walker N. Predicting cholangiocarcinoma in patients with primary sclerosing cholangitis. Gut 1991; 32: 1369-73.

21 Christianssen E, Altman DG, Neuberger J, De Stavola BL, Tygstrup $\mathbf{N}$, Williams $R$. Updating prognosis in primary biliary cirrhosis using a time dependent primary biliary cirrhosis using a time dependent cox regressi.

22 Prochazka EJ, Terasaki PI, Park MS, Goldstein LI, Busuttil RW. Association of primary sclerosing cholangitis with HLA-DRw52a. N Engl $f$ Med 1990; 322: 1842-4.

23 Zetterquist H, Broomé U, Einarsson K, Olerup O. HLA class II genes in primary sclerosing cholangitis and chronic inflammatory bowel disease: no HLA-DRw52a association in Swedish patients with sclerosing cholangitis. Gut 1992; 33: 942-6.

24 Donaldson PT, Farrant JM, Wilkinson ML, Hayllar K, Portmann BC, Williams R. Dual association of HLA DR2 and DR3 with primary sclerosing cholangitis. Hepatology 1991; 13: 129-33.

25 Olerup O, Olsson R, Hultcrantz R, Broomé U. HLA-DR and $\mathrm{DQ}$ alleles are not markers for rapid disease progression in Swedish patients with primary sclerosing cholangitis Gastroenterology 1995; 108: 870-8.

26 Mehal WZ, Lo YMD, Wordsworth BP, Neuberger JM, Hubscher SC, Fleming KA, et al. HLA DR4 is a marker for rapid disease progression in primary sclerosing cholangitis. Gastroenterology 1994; 106: 160-7. 